\title{
Article
}

\section{Locating Community among People with Schizophrenia living in a Diverse Urban Environment}

Kidd, S.A., Frederick, T, Tarasoff, L, Virdee, G, Lurie, S, Davidson, Lesley, Morris, David and McKenzie, K

Available at http://clok.uclan.ac.uk/11392/

Kidd, S.A., Frederick, T, Tarasoff, L, Virdee, G, Lurie, S, Davidson, Lesley, Morris, David ORCID: 0000-0001-7372-8084 and McKenzie, K (2016) Locating Community among People with Schizophrenia living in a Diverse Urban

Environment. American Journal of Psychiatric Rehabilitation, 19 (2). pp. 103121. ISSN ISSN: 1548-7768 (Print)

It is advisable to refer to the publisher's version if you intend to cite from the work. http://dx.doi.org/10.1080/15487768.2016.1162757

For more information about UCLan's research in this area go to http://www.uclan.ac.uk/researchgroups/ and search for <name of research Group>.

For information about Research generally at UCLan please go to http://www.uclan.ac.uk/research/

All outputs in CLoK are protected by Intellectual Property Rights law, including Copyright law. Copyright, IPR and Moral Rights for the works on this site are retained by the individual authors and/or other copyright owners. Terms and conditions for use of this material are defined in the policies page.

\section{CLoK}

Central Lancashire online Knowledge www.clok.uclan.ac.uk

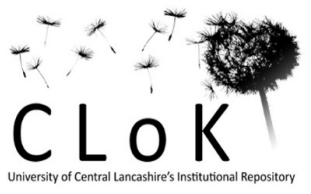




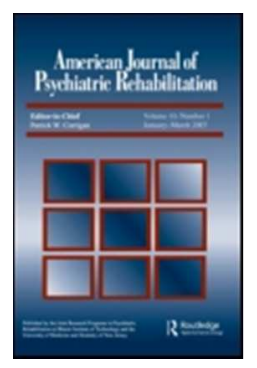

\section{Locating Community among People with Schizophrenia living in a Diverse Urban Environment}

\begin{tabular}{|r|l|}
\hline Journal: & American Journal of Psychiatric Rehabilitation \\
\hline Manuscript ID: & UAPR-2014-0022.R1 \\
\hline Manuscript Type: & Original \\
\hline Keywords: & $\begin{array}{l}\text { Community, Schizophrenia, Severe Mental Illness, Social Integration, } \\
\text { Poverty, Rights, Diversity }\end{array}$ \\
\hline \multicolumn{2}{|l}{} \\
\hline
\end{tabular}

SCHOLARONE $^{\text {"x }}$

Manuscripts 
Increasing the community participation of people with severe mental illness is a primary goal of recovery-oriented services worldwide (World Health Organization, 2013). National mental health strategies position engaged and accessible communities as a cornerstone of mental health reform (e.g., Mental Health Commission of Canada, 2012). Furthermore, there is a movement towards communities (rather than governments) "tak[ing] more responsibility" for challenges like mental illness (e.g., UK ‘Big Society’ movement; The Cabinet Office, 2010, p.1). However, in these contexts the concept of "community" and its associated characteristics and processes are used very broadly and seldom defined. This type of ambiguity can greatly limit the impact of policies and mandates, leading to poorly conceptualized implementation strategies and wasted investments (Matland, 1995). However, the concept of "commmnity" is poorly defined in this context, as are the mechanisms through which people are able to engage potential communities. RFFor years, researchers attuned to this problem have been calling for an intensive inquiry of the meanings and processes of community involvement participation across its many dimensions (Baumgartner \& Herman, 2012; Farone, 2006; Royce-Davis, 2001; Townley, Kloos, Wright, 2009). In this paper we describe the qualitative findings from a longitudinal study of community participation among a diverse group of urban-dwelling individuals with schizophrenia in Canada.

\section{Community Participation}

Community participation (often used interchangeably with terms such as inclusion,' 'involvement,' and 'engagement') is conceptualized as an individual's social and emotional 
connections to and within a place, created through personal meanings (Royce-Davis, 2001;

Walker, 1995). Community, in turn, can be characterized across at least three dimensions:

(i) a physical presence dimension, involving the types and frequency of use of physical spaces, goods, and services;

(ii) a social dimension, involving the types and amount of social interactions in the community; and,

(iii)a psychological dimension, involving the individual's perceptions about membership in the community (see Royce-Davis, 2001, and Yanos, Felton, Tsemberis \& Frye, 2007 for reviews).

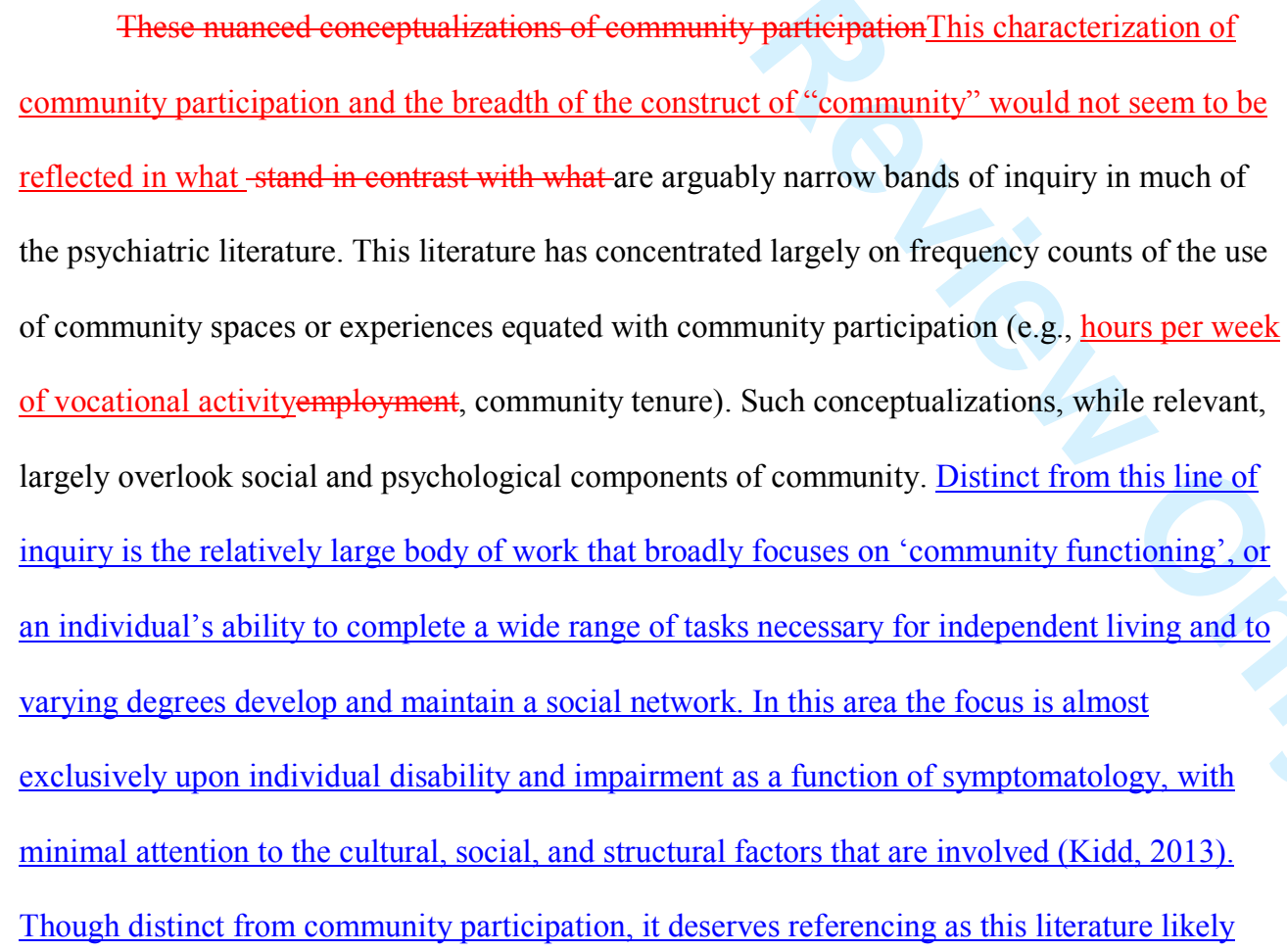


serves as an explanatory model for challenges with community participation that are observed by $\underline{\text { service providers and researchers alike. }}$

\section{Factors Associated with Community Participation}

In general, it has been found that younger age, better engagement in the recovery process, lower severity of illness, and fewer behavioural manifestations of psychiatric illness are associated with participation in community activities (Davis, Townley \& Kloos, 2013; Gulcur, Tsemberis, Stefancic \& Greenwood, 2007; Ingamells, Goodwin \& John, 1996; Aubry, Teft \& Currie, 1995). The characteristics of neighbourhoods have also been examined. Yanos et al. (2007) found little association between community participation and type of neighbourhood (degree of stability of residence, concentration of immigrants, level of economic disadvantage), though Segal, Baumohl and Moyles (1980) found greater degrees of acceptance associated with liberal, non-traditional and working class neighbourhoods. Perceptions of community would also seem important as demonstrated by Prince and Prince (2002), who found that higher levels of perceived stigma were associated with lower community activity levels, and by Kloos and Townley (2011), who found that the perceptions of a better neighbourhood social climate has an inverse relationship with psychological distress.

More recently researchers have begun to examine associations with community participation as a function of individual characteristicsef subpopulation. For example, while younger and older adults both experience a strong link between quality of life and community participation, Kaplan and colleagues (2012) found emphases among youth on educational involvement and friends, while for mature adults emphases were upon parenting, spirituality, and 
peer-support. Another study indicated that while women struggled to a lesser extent with social inclusion, themes of safety of living environment were more pivotal (Manuel, Hinterland, Conover \& Herman, 2012).

\section{Qualitative Literature}

While there is a substantial body of qualitative literature emphasizing the importance of social inclusion in recovery (Davidson, 2003), there is a paucity of qualitative work documenting community participation beyond the noting of general themes and concepts. There is broad commentary on the importance of a stable sense of home in facilitating meaningful community participation (Kirkpatrick \& Byrne, 2009), and it has been found that employment leaves people feeling more connected with their communities and less stuck and stigmatized within the role of the 'mental patient' (Borg \& Kristiansen, 2008). Work that more specifically examines community participation has emphasized the challenges faced due to discrimination in community settings where people felt "locked into their roles as 'mental patients"' (Mezzina et al., 2006, p. 45). Yanos, Barrow and Tsemberis' (2004) qualitative study of 80 Housing First study participants revealed that a sense of 'fitting in' to the community was impacted by the degree of ethno-racial similarity and similarity in perceived values in the local community. Recent work addressing diversity and marginalization has documented how multiple forms of intersecting discrimination (financial, racial, mental illness, sexual identity, gender) interact with community characteristics to impede participation (Kidd et al., 2011; 2013a; 2013b).

A more consistent finding in the qualitative literature is that informal, casual contacts (e.g., local merchants, staff, and members of recreation centres) can be important avenues for 
reciprocal relationships since they are less demanding and less likely to be stressful (Davidson et al., 2001). Such contacts serve as a means through which people can gain confidence and hope in the recovery process (Mezzina et al., 2006).

Aims

Overall, the amount and scope of research in this area lies in marked contrast with the community rhetoric that pervades service and policy dialogues. To further this line of investigation we used an intensive qualitative inquiry to address the following question: What experiences, beliefs, behaviours, and spaces constitute community participation for people with severe mental illness? This study is among the first to intensively examine the many characteristics and intersecting elements of resilience and adversity that are associated with attend "community" for people with severe mental illness. It focuses upon an ethnically diverse group of individuals residing in inner-city neighbourhoods in a large Canadian city.

\section{Method}

\section{Study Setting and Participants}

This study took place in five diverse inner-city neighbourhoods in the downtown core of a large Canadian urban setting. In each of these neighbourhoods the largest racialized groups are individuals of White European, African Caribbean, South Asian, and East Asian descent (City of Toronto, 2010). The participants in this study are individuals with schizophrenia or a psychosis spectrum major-mental illness. A stratified purposeful sampling strategy was used to recruit a balanced sample with respect to the above racialized identities. Addressing ethno-cultural diversity is a critical component of this study, as diversity is poorly reflected in the community 
and recovery literatures as a whole (Kidd et al., 2013a). For all subgroups, we sought a balance in place of residence, gender, age, hospitalization history, and housing circumstances. Recruitment was facilitated by care providers across a range of settings (hospital, community service, boarding home). The study was reviewed and approved by the Research Ethics Board at the Toronto Centre for Addiction and Mental Health.

\section{Method of Inquiry}

We collected detailed demographic data from each participant. This included gender identity, sexual orientation, relationship status, racial and ethnic background, country of origin, time since immigration, religious affiliation, age, housing type, sources of income, education level, and hospitalization history.

A semi-structured qualitative interview was developed from community theory literatures ${ }^{4}$ with the domains of qualitative inquiry-qualitative questions derived from quantitative surveys such as the External Community Integration Scale (Manzo \& Perkins, 2006), the Sense of Community Index (Perkins, Florin, Rich, et al. ,1990), measures of perceived neighbourhood social cohesion (Sampson, 1997), the Devaluation-Discrimination Scale (Link, 1987), and the evaluation framework of Aubrey and Myner (1996). Three times over the course of approximately 10 months, with interviews taking place at the beginning, in month 5 , and at the end of this period, -participants spent between 6-8 hours (within a 1 week period) completing in-depth interviews focusing on all domains of community participation (i.e., physical, psychological, social, economic, spiritual, political). Along with 1-1 semi-structured interviews, participants took the interviewer on a tour of their communities on foot and by transit (field notes were used to document conversation about community while traveling), and engaged in social 
resource mapping using maps through which the participants created a visual representation of their communities as they described their activities and experiences_(GIS analysis findings reported elsewhere; Daywithheld to maintain blinded review et al., 2014). This study also included over 100 interviews with neighbourhood stakeholders (e.g., coffee shop clerks, police, librarians, spiritual leaders). These interviews focussed on their beliefs and experiences related to issues of inclusion and barriers in the community and their own spaces as they relate to persons with mental illness accessing resources (findings reported elsewhere; withheld to maintain blinded reviewKidd et al., 2014). All interviews were audio-recorded and transcribed verbatim with field notes used to capture observations and informal interactions.

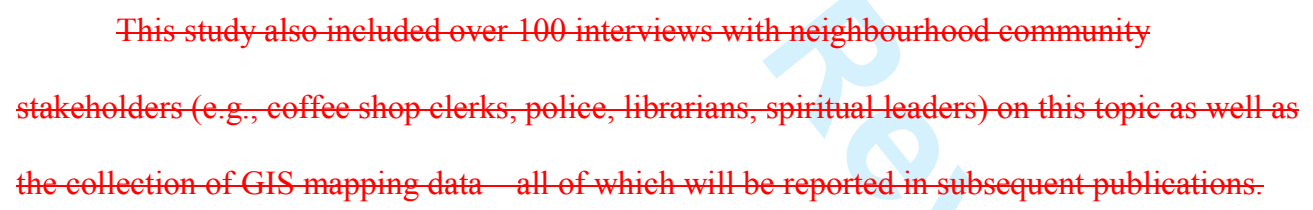

\section{Data Analysis}

All field notes and transcribed audio recordings were analyzed using the coding strategy articulated by Charmaz (1995), attending to the integration of ethnographic methods as recommended by Charmaz and Mitchell (2001). While the goal of this study was not the development of theory, this analysis strategy was chosen for its rigor, particularly within a design involving multiple contacts over time. First, common themes/categories were derived through an open coding process. Second, there was a movement toward developing conceptual categories. Throughout the above process memos were used to document and inform the analysis process. Several steps were taken to maximize rigor in the analysis and to establish the credibility and 
trustworthiness of the findings. First, we obtained in-depth narratives, carefully took field notes documenting observations and reactions, and coded verbatim transcripts line by line. Second, we engaged participants in discussions about the emerging categories and themes as described above. This process deepened the discussion of the core emergent constructs and helped ensure better alignment of our understandings of the themes with the participants' meanings. Third, we conducted detailed reviews of the code structure by the research team (checking categories against original text; reviewing all coded text; having dialogue and feedback about coding structure). The analysis was completed by --, --- and -- with -- taking a lead in integrating findings. Preliminary findings were also reviewed over the course of the study by an advisory group of individuals with lived experience of mental illness. This input assisted in refining the inquiry and critically considering the findings.

Interviewing and data analysis were undertaken by a Sociologist, Public Health and Counselling Psychology graduate students, and a Clinical Psychologist. This group had as an advisory a group comprised of experienced service providers, equity researchers, and individuals with lived experience of mental illness. In the course of the study this group was struck both by the tremendous diversity of experiences and activities that attend-comprised "community participation" and by the resilience and creativity with which participants strove to create active and meaningful lives in impoverished contexts.

\section{Results}

The participants were 30 individuals with schizophrenia or a psychosis spectrum severemajor mental illness. The mean age was $45(\mathrm{SD}=10.9), 43 \%$ of the sample attended or 


\section{Social Relationships}

Relationships with others variously expanded and constricted participants' engagement with community. One major theme was informal and, often, superficial interactions with members in the community - typically people involved in businesses or publically accessible spaces offering various kinds of resources.

\footnotetext{
“There's a convenience store....His name's Mr. [----]. He's Korean...I just started talking to him one day and he told me he was in the South Korean air force and in the Korean War, and that him and his family came to Canada. He's a nice man...We just started talking about Korea...”
} 
Locating Community 12

\begin{abstract}
Whether a coffee shop, a library, or a charitable organization offering meals or programming, people gravitated towards spaces that met their needs, were affordable, safe, and welcoming. Feeling welcome was not solely about mental illness but was also about race and socioeconomic status, and a general sense of "fitting in." Herein was a general desire to be a part of things - to be out in the world and around other people, without it necessarily involving demanding social interactions.
\end{abstract}

\begin{abstract}
"People in my neighbourhood are not friendly...but I go to stores [gave example of a pharmacy chain] where I don't feel that I'm skin colour or Negro. ...I talk to some stores like [pharmacy]. I don't feel that have anything against my skin colour..."
\end{abstract}

Beyond non-discrimination, many participants went to spaces where they could find people who they felt were similar to them (e.g., along socioeconomic, ethnic, or mental illness identity lines). The basis of similarity depended on the person and was variable - one day it might feel important to be around people with the same racial and ethnic identity and on another to be around other people who have experienced mental illness. Similarity along the lines of race and ethnicity emerged particularly important for first generation immigrants identifying as African Caribbean and East Asian.

"It's a great place, an urban place, lots of black people... when I get to be around my, you know, my people, I get to fit right in" 
“[I go to] my sister's at least once a week.... My one sister who's younger than me, we spend a lot of time together and I really enjoy that.... Sometimes we eat out. Sometimes

we just go for a coffee or a walk"

"Yeah, I like Spadina, I love Chinatown....Because I like many Chinese people. They speak same language, Cantonese language. And they have two shopping malls. There's Dragon City Mall...and Mandarin shopping mall too, large. Mandarin Centre"

Family represented an often complicated presence in relation to community. Most participants had limited contact with family. Family relationships deteriorated due to (i) the instability of the mental illness itself, (ii) being stigmatized by family due to their having a mental illness, (iii) the sense of no longer having a place with family members who lived more affluent lives and, (iv) logistical difficulties of travel to family homes and an unsuitability, due to impoverished conditions, of their own residences for family to visit. "They are married, they are busy with their family.... I don't see them very often" ; "I don't think any of them are stigmatizing me by any means. I just think that some of them get busy with their own lives. And they're dealing with their own stresses, you know." In contrast, for some, connection with family was a major facilitator of access to non-illness related community spaces, for example malls, online community, travel out of low income spaces, and nicer restaurants. For immigrants, in particular, their sense of community was extended through the use of social networking technology which facilitated the maintenance of these relationships. 
Both friendships and romantic relationships were further complicated by poverty, which circumscribed opportunities to engage in activities with others. In the context of limited financial resources to pursue social and leisure activities, boarding homes could be places where friendships could be cultivated and traumatizing past experiences with social contacts and relationships resolved. "I hate the men in India.... I had a strong hatred for men. I hated men for 
“And I don't, I don't...I like to have friends but I don't need friends. The reason is because you have friends and you help them with money and they think it's a gift and they never repay the money. It happened to me once. $\$ 200$. Somebody rips me off. Now I'm really careful about choosing my friends. And I have no friends because they're hardly loyal, eh.” .

Service providers were a key relationship in the lives of many - often being the only people that participants had in their lives that were a regular source of support. Appointments with workers and spending time at outpatient drop-ins were also a central activity for many and gave structure to their days and weeks. Additionally, caseworkers and nurses were described as at times helping participants connect with educational opportunities, volunteering, and other community-based activities. This included spaces that were of cultural significance, for example faith spaces and community groups and repairing strained family relationships within the framework of collectivist family-based cultures. Conversely, it was also not uncommon for service providers to be markedly out of touch with their client's community experiences - either misjudging the amount of community involvement the person has or issuing broad recommendations without understanding the processes involved. 
“My doctor, my physician told me I need to break out of my shyness... [but] I don't know how to talk to [people]. When I meet somebody I don't really want to talk too much. I'm quiet. If you don't say hi, I won't say hi."

\section{Self-Concept}

The second major grouping of themes centred upon self-concept. By self-concept we are referring here to a person's thoughts and feelings about her or his self which are, in turn, , which are closely linked with decisions to act or not made in reference to this understanding of the selfkey reference points in determining an individual's actions and beliefs (Schlenker, 2012). Across all ethnic groups, participant life stories were trajectories that began with their being embedded in mainstream forms of community early in life. Then, through narrowing pathways of increasing poverty and marginalization, interactions with aspects of community associated with mental illness (services, social spaces, community places) became predominant.

How the self is considered in reference to her or his communities was critical to life satisfaction and sense of wellness -"The right community can be the difference between feeling like you're living or dying." Many perceived their lives as ones of accumulating distance from the communities in which they began - a distance that was at least in part influenced by exposure to psychiatric "institutions" where non-illness identity was lost and life expectations lowered. For many racialized South Asian, East Asian, and African Caribbean-origin and first or second generation immigrant participants, the process of marginalization was further compounded through intersecting forms of discrimination - be it racial or struggling to attain status through byzantine immigration policies. 
“I don't think it's because of my mental illness, but I think it's just because of my skin colour you know because I was a landed immigrant, and I got discriminated against you know.... because of my socio-economic background you know what I mean".

In contrast, for participants from family-based cultureshighly family-centric cultures (particularly common among South Asian-origin participants), there could be some relief in the relinquishing of their pre-illness identity, as this process often involved creating some physical | and psychological separation from family and cultivating a more independent sense of self (themes of race and ethnicity examined in detail in Withheld to maintain blinded review et al., 2014).

Participants across ethnic groups described taking action in their lives to establish a positive self-concept or otherwise having hopes that someday their community involvement might better align with where they believed they should be positioned. "When I was at [hospital] I didn't feel like I was somebody there... once I got out and then back to school I got better. Things started clearing up." Additionally, some at times jumped the mental illness-mainstream divide $_{2}$ if only briefly. This included spending a large part of their budget, enough to position them briefly in a community context in which they could feel that their activities aligned with valued aspects of self-concept (more expensive restaurant, shopping), though they often paid the price for this later with greater deprivation. 
"For a while I was going to [a steakhouse] for lunch. And so that's expensive, but my money goes fast anyways and I really enjoy the steak there. My workers don't want to see me go [there] ... they think it's too much money for me to spend at one place. They want my money to last for the month. If I eat out a lot, it won't last... I have to go hungry for two weeks".

This overlay of self-worth related to community participation emerged in many contexts, * from "embarrassment" about going to drop-ins and being in neighbourhoods that exemplify poverty and low social position to avoiding ethnic communities of origin to be more "Canadian," which had roots in traumatic experiences in their country of origin.

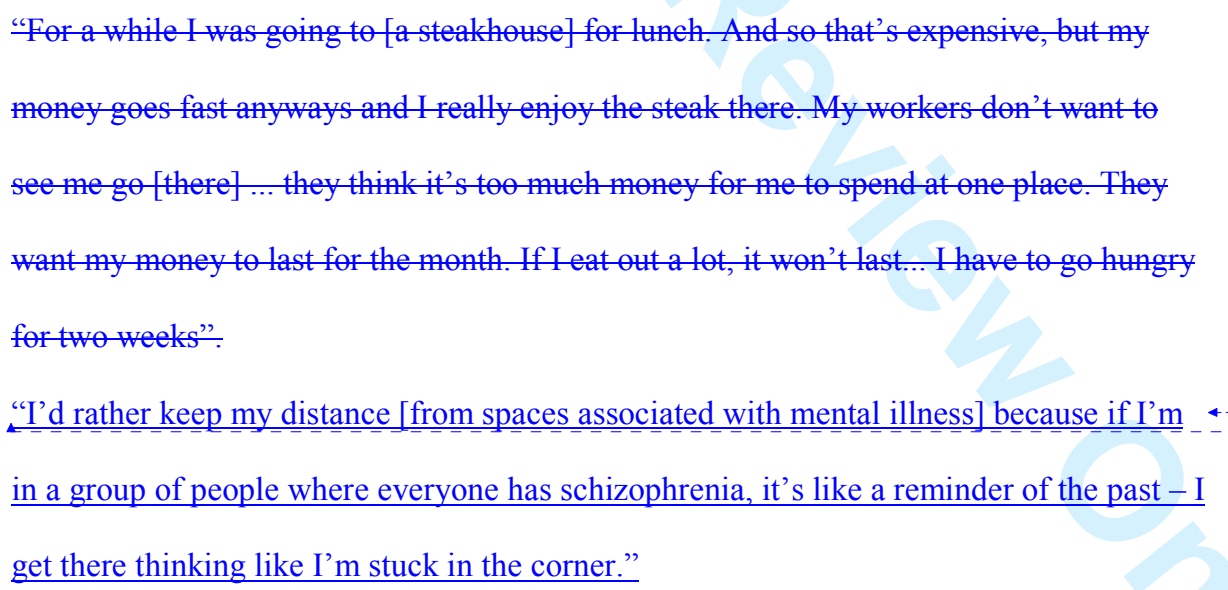

In contrast, some participants described stepping back from this conflictual interface between self and community, finding it more comfortable spending time in contexts associated with mental illness. One man went so far as to say he found it "liberating" to "succumb" to identifying with the mental illness community and disengaging from the struggle to re-engage 


\section{Resource Acquisitions}

The third and most heterogeneous of the themes was the role that resources and resource acquisition played in structuring community interactions and involvement. Of all themes, across every area, for participants across ethnic groups, poverty was the most cross cutting.

"It's a struggle, it's hard, it's really hard, you know, schizophrenia, it affects me in a lot of ways, because it's like my living standards are lower man, you know before I used to work, before I got sick and now I am like living on disability and I am struggling.”

Poverty limited a person's ability to travel, to enter particular spaces, to purchase valued goods and services, and to cultivate the physical appearance required to feel comfortable in stores and restaurants. Resonant within this theme were narratives of isolation and exclusion and the constant calculating of what can be afforded. 
"I have to be cautious. I don't get deluxe pizza; it's too expensive; I just get a couple of toppings so I'm reasonable. I worry about things..."

Poverty also forced people to reside in buildings and city areas in which victimization, violent or otherwise, was more likely - a prominent concern among those who have been victimized in the past and who were struggling with associated trauma (e.g. political, sexual). This was described as greatly limiting movement in communities, particularly at night. It also prevented people from accessing particular social services because they were seen as being understaffed and unable to effectively cope with violent and unruly behaviour. While an issue for all participants, concerns about victimization were most often emphasized in the narratives of women.

\begin{abstract}
“The building I live in, it's basically a drug haven. It's like it's a 24 hour in and out. Security guards...we go through a lot of security companies because nobody wants to really stay there 'cause people get really aggressive when they want their drugs and they can't come in."
\end{abstract}

Movements were further dictated by services and spaces that need to be accessed to Formatted: Indent: Left: $0^{\prime \prime}$ obtain food, various kinds of treatments and medications, and other necessities of daily living. Narratives in this area were characterized by constrictions in choice, be it mandatory appointment attendance, difficulty addressing specific ethnic food desires or requirements (e.g., Halal food), meal times at charitable organizations or boarding homes, curfews, and generally "military" type rules dictating conduct in various spaces. These types of rules and restrictions 
had implications for community participation that extended considerably beyond the specific settings for which they were intended.

This was further complicated for some participants because of their neighbourhood, and the subsequent limited access to their specific ethnic or religious foods for example Caribbean or Halal foods.

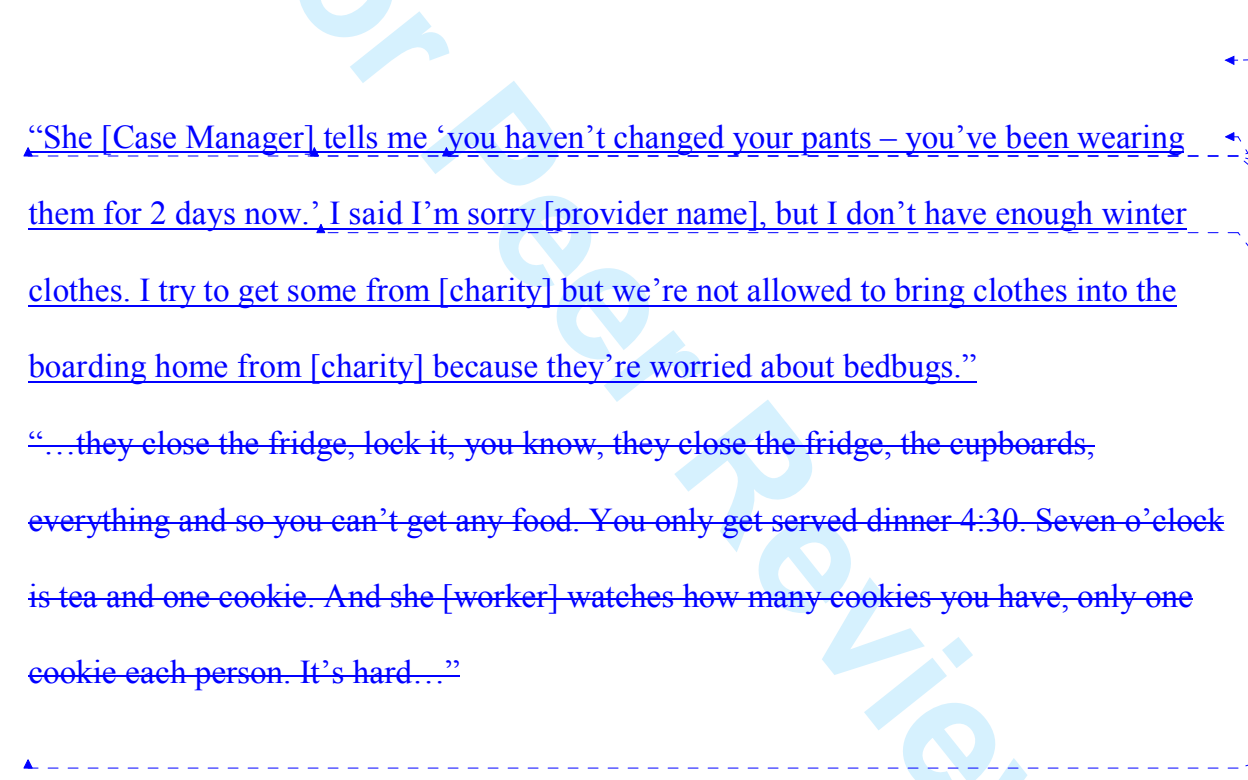

\section{Discussion}

Among this diverse group of individuals with psychosis residing in dense ethnically diverse inner-city neighbourhoods, community participation is the outcome of a dynamic transaction that is shaped by illness and non-illness associated relationships and spaces, selfconcept, and the institutions and resources accessible to the person.

As commented upon previously (Davidson et al., 2001; Salzer et al., 2014), a large component of community participation took the form of casual contacts with the staff members 
of accessible spaces such as coffee shops and stores. Also similar to past work was the finding that successful efforts to engage community resources were associated with a better general sense of wellness (Davis et al., 2013).

Where this study expands upon previous work lies in how the participants across ethnic groups in this study explained their community participation as multifaceted and dynamic. As is the case for most people, with or without mental illness, participants sought out a range of spaces in which they might feel welcome and comfortable, with at least some of this sense of comfort having to do with being around people seen as similar to themselves. There were, however, several unique factors linked with having the social position of a person with a severe mental illness and its corollaries of poverty, discrimination, and social marginalization, that had a major role in the dynamics of community participation. Additionally, for many, community participation was further influenced as mental illness intersected with experiences of migration, ethnicity, and race.

Family was repeatedly referenced in these narratives, primarily in the form of positioning one's place in community - a place that is often very different from the family community contexts in which their lives began. For most, when the limited contact with family occurred, it involved a distinct logistically challenging movement out of one's home community - often to either a 'neutral' space such as a restaurant or mall or to a relatively wealthy suburban setting that emphasized how different one's life is from that of one's family. Reaction to this distance from communities of origin varied. For some it was a source of ongoing distress while for others it had ceased being a consideration as their personal community no longer included family. Some 
Furthermore, these findings highlight the complexity that lies behind observations such as those of Metraux et al., (2012) that, in dense urban environments, the community integration context for individuals with severe mental illness may be changing from "service ghettos" to 
better than average proximity to clusters of small businesses and other amenities. In the Toronto context, the rapid gentrification of downtown neighbourhoods would seem to have cultivated geographies that might be characterized as ones in which 'you can look but don't touch.' Local businesses are becoming increasingly upscale and expensive, transit costs are increasing, and while violence and victimization might be less overt in the streets it is certainly very active in the hallways, lobbies, and courtyards of the buildings in which many of our participants reside. Additionally, the time and transit required to attend appointments and compliance with the stringent rules of boarding homes and other service-oriented spaces further restrict an individuals freedom of movement.

Also minimally documented in the community literature is the role of self-concept. Selfconcept and community participation were inseparable and had a dynamic relationship. For most, the distance between the communities in which they felt they belonged and the reality of participating in communities associated with mental illness and poverty was deeply distressing. Indeed, travel to various mental health appointments comprised a very large component of movement within the communities of participants. This disconnect between self-concept and community participation prompted the formation of life goals (i.e., to get back to enfranchised community and, by implication, valued self) and the seeking out of temporary spaces of refuge. Refuge often took the form of avoiding spaces where people known to have mental illness frequent or by spending a relatively large amount of money to access a non-poverty/non-mental illness associated space such as a nice restaurant. Others, however, did not engage in the stress and conflict associated with this divide. Some no longer sought out communities not linked to mental illness in a manner reflective of fatigue from defeated efforts, exposure to stigmatizing 
Such findings readily reflect the large body of literature on self-concept. How one views oneself cannot exist in isolation from social, and by proxy, community contexts. Our sense of self is created and confirmed through feedback from our social environment (Davidson et al., 2001). As the mental illness itself impacts people's ability to engage in community and systemic discrimination drives one's self-concept and communities of residence into marginalized positions, recovery, in turn, requires resistance and growth at self and community participation levels. The recovery process is indeed the recovery of valued aspects of self (parent, employee, film enthusiast) and associated activities that transcend and minimize the space taken up by mental illness in one's self and community. As extensively documented in self-concept literatures (Schlenker, 2012), coherence plays a role in that sharp contradictions between self-concept (e.g., an intelligent and contributing person) and community participation (e.g., denial of access to community resources due to poverty and discrimination) are distressing. In such contexts, individuals such as the participants in this study variably (i) engage remarkable resilience in persistent efforts to re-connect with non-marginalized community, (ii) are highly active and creative in using accessible community resources in ways that bolster a valued sense of self, or to some extent (iii) address self-concept discrepancies by accepting the marginalized position and trying to find some modest quality of life therein. Given the extent of the adversity faced, it is indeed remarkable that the majority do successfully engage in recovery with its implications for valued self and community (Warner, 2005). However, as observed in other work (Salzer et al., 2014), there clearly exists a challenge in broadening the spectrum of community participation to 
include domains where systemic discrimination can exert a greater influence (e.g., access to employment).

This study has several limitations. First, because it was conducted in a single Canadian urban setting, it is difficult to comment on the transferability of the findings. Second, in relegating the study to downtown neighbourhoods, we were not able to address the issues that attend the inner suburbs of cities. This is relevant in that there is evidence that gentrification of downtown city neighbourhoods is leading to increasing numbers of impoverished people with mental illness moving to less expensive inner suburbs (Metraux, Busilovskiy, \& Prvu-Bettger et al., 2012). Issues such as the "vertical poverty" of large subsidized apartment buildings and heightened challenges associated with the travel needed to access resources cannot be addressed here. This is an important area for future work, as well as expansion to mid-sized cities and rural areas. Finally, while having extensive contact over a 10-month period assisted in deepening the qualitative analysis, this was not a sufficient time period to capture community participation as it evolves over periods of years rather than months.

There are several practical implications of this work. Service providers were described as having the potential to be helpful in facilitating access to resources, but also commonly misinformed about what "community" involves for their clients. Broad admonitions to increase community activity levels are likely counterproductive when applied to persons already extremely busy subsisting and navigating adverse environments that bear little resemblance to contexts where "getting out more" is readily achieved. Engaging in clinical work that is informed by a more thorough assessment of existing challenges and resources related to community 
participation would seem more likely to be successful. In other words, aligning interventions with the context of people's lives, including where they live, where they come from, and the various intersecting social locations they may occupy, is pertinent and needed.

Furthermore, in both research and clinical domains, there would seem to be a need to critically examine the predominant "functional impairment" narrative for explaining challenges in community functioning and better attending to the systematic forms of adversity and discrimination described here. This is further supported by the manner in which "impairment" rhetoric is contradicted by just how little variance in community functioning is predicted by symptomatology (Fett, Viechtbauer, \& Dominguez et al., 2011; Kidd, 2013). More substantively, however, these narratives stand in stark contrast with abundant use of "community" as a resource in practice and policy dialogues. From the blatant to the insidious, these individuals described what are certainly major ethical issues, if not rights violations, in how individuals with mental illness are treated in the "communities" to which many are relegated. These realities need to be held up against rhetoric about taking better advantage of community resources and the citing of explanations of failed psychiatric interventions or illness-framed problems such as 'defeatist beliefs' eited-as the reasons why full community participation is seldom attained. 
Aubry, T., \& Myner, J. (1996). Community integration and quality of life: A comparison of persons with psychiatric disabilities in housing programs and community residents who are neighbours. Canadian Journal of Community Mental Health, 15(1), 5-20.

Aubry, T. D., Teft, B., \& Currie, R. F. (1995). Public attitudes and intentions regarding tenants of community mental health residences who are neighbors. Community Mental Health Journal,31, 39-52.

Baumgartner, J.N., \& Herman, D. (2012). Community integration of formerly homeless men and women with severe mental illness after hospital discharge. Psychiatric Services, 63, 435437.

Borg, M., \& Kristiansen, K. (2008). Working on the edge. Disability and Society, 23(5), $511-23$.

Charmaz, K. (1995). Grounded theory. In J. A. Smith, R. Harre \& L. V. Langenhove (Eds.), Rethinking methods in psychology (pp. 27-49). Thousand Oaks, CA: Sage.

Charmaz, K., \& Mitchell, R.G. (2001). Grounded theory in ethnography. In P. Atkinson, A. Coffey, S. Delamont, J. Lofland, \& L. Lofland (Eds.). Handbook of Ethnography. (pp.160-174). Thousand Oaks, CA: Sage.

City of Toronto. (2010). Toronto neighbourhood maps. http://www.toronto.ca/demographics/profiles_map and index.htm. Downloaded, January $14,2010$. 
Davidson, L., Haglund, K., Staynor, D., Rakfeldt, K., Chinman, M., \& Tebes, K. (2001). "It was just realizing....that life wasn’t just one big horror.": A qualitative study of supported socialization. Psychiatric Rehabilitation Journal, 24, 275-292.

Davidson, L. (2003). Living Outside Mental Illness: Qualitative Studies of Recovery in Schizophrenia. New York City: New York University Press.

Davis, B., Townley, G., \& Kloos, B. (2013). The roles of clinical and non-clinical dimensions of recovery in promoting community activities for individuals with psychiatric disabilities. Psychiatric Rehabilitation Journal, 36, 51-53.

Farone, D. (2006). Schizophrenia, community integration, and recovery. Social Work in Mental Health, 4. 21-36.

Fett, A-K., Viechtbauer, W., Dominguez, M., Penn, D., van Os, J., \& Krabbendam, L. (2011).The relationship between neurocognition and social cognition with functional outcomes in schizophrenia: a meta-analysis. Neuroscience and Biobehavior Review, 35, $573-588$.

Fitzgerald, P., De Castella, A., Filia, K., Filia, S., Benitez, J., \& Kulkarni, J. (2005). Victimization of patients with schizophrenia and related disorders. Australia and New Zealand Journal of Psychiatry, 39, 169-174.

Gulcur, L., Tsemberis, S., Stefancic, A., \& Greenwood, R. (2007). Community integration of adults with psychiatric disabilities and histories of homelessness. Community Mental Health Journal, Vol. 43: 3, 211-228.

Ingamells, S., Goodwin, A. M., \& John, C. (1996). The influence of psychiatric hospital and community residence labels on social rejection of the mentally ill. British Journal of Clinical Psychology, 35, 359-367. 
Kidd, S.A. (2013). From Social Experience to Illness Experience: Reviewing the Psychological Mechanisms Linking Psychosis with Social Context. Canadian Journal of Psychiatry, 58, $\underline{52-58 .}$

Kidd, S.A., Veltman, A., Gately, C., Chan, K.J., \& Cohen, J.N. (2011). Lesbian, gay, and transgender persons with severe mental illness: Negotiating wellness in the context of multiple sources of stigma. American Journal of Psychiatric Rehabilitation, 14, 13-39.

Kidd, S.A., Virdee, G., Quinn, S., Toole, L., McKenzie, K., \& Krupa, T. (2013a). Racialized Women with Severe Mental Illness: An Arts-Based Approach to Locating Recovery in Intersections of Power, Self-Worth, and Identity. American Journal of Psychiatric Rehabilitation, 2014, 17, 20-43.

Kidd, S.A., Virdee, G., Krupa, T., Burnham, D., Hemingway, D., Margolin, I., Patterson, M., \& Zabkiewicz, D. (2013b). The role of gender in housing for individuals with severe mental illness: A qualitative study of the Canadian service context. British Medical JournalOpen, 3:e002914.

Kirkpatrick, H., \& Byrne, C. (2009). A narrative inquiry: Moving on from homelessness for individuals with a major mental illness. Journal of Psychiatric and Mental Health Nursing, 16, 68-75.

Kloos, B., \& Townley, G. (2011). Investigating the relationship between neighborhood experiences and psychiatric distress for individuals with serious mental illness. Administration and Policy in Mental Health, 38, 105-116. 
Link B. (1987). Understanding labeling effects in the area of mental disorders: an assessment of the effects of expectations of rejection. American Sociological Review, 52, 96-112.

Manuel, J., Hinterland, K., Conover, S., \& Herman, D. (2012). "I hope I can make it out there.”: Perceptions of women with severe mental illness on transition from hospital to community. Community Mental Health Journal, 48, 302-308.

Manzo, L., \& Perkins, D. (2006). Finding common ground: The importance of place attachment to community participation and planning. Journal of Planning Literature, 20, 335-350.

Matland, R. (1995). Synthesizing the implementation literature. Journal of Administration Research and Theory, 5, 145-174.

Mental Health Commission of Canada (2012), "Changing direction, changing lives: The mental + health strategy for Canada", Mental health commission of Canada, Calgary.

Formatted: Font: Times New Roman, $12 \mathrm{pt}$

Formatted: Indent: Left: 0", Hanging: 0.5", Space After: $10 \mathrm{pt}$, Line spacing: Multiple 1.15 li Formatted: Font: Times New Roman, 12 pt Formatted: Space After: $10 \mathrm{pt}$ Formatted: English (Canada)

Metraux. S., Brusilovskiy, E., Prvu-Bettger, J., Wong, Y-L., \& Salzer, M. (2012). Geographic access to and availability of community resources for persons diagnosed with severe mental illness in Philadelphia, USA. Health and Place, 18, 621-629.

Mezzina, R., Borg, M., Marin, I., Sells, D., Topor, A., \& Davidson, L. (2006). From participation to citizenship: How to regain a role, a status, and a life in the process of recovery. American Journal of Psychiatric Rehabilitation, 9, 39-61.

Perkins, D.D., Florin, P., Rich, R.C., Wandersman, A., \& Chavis, D.M. (1990). Participation and the social and physical environment of residential blocks: Crime and community context. American Journal of Community Psychology, 18, 83-115.

Prince, P., \& Prince, C. (2002). Perceived stigma and community integration among clients of assertive community treatment. Psychiatric Rehabilitation Journal, 25, 323-331. 
Royce-Davis, J. (2001). "It's the day to day that matters.": The meaning and process of community in the lives of a couple with significant psychiatric difficulties. American Journal of Community Psychology, 29, 807-832.

Salzer, M., Brusilovskiy, E., Prvu-Bettger, J., \& Kottsieper, P. (2014). Measuring community participation of adults with psychiatric disabilities: Reliability of two modes of data collection. Rehabilitation Psychology, 59, 211-219.

Sampson, R.J. 1997. Collective regulation of adolescent misbehavior: validation results from Chicago neighborhoods. Journal of Adolescent Research, 12, 227-44

Schlenker, B. (2012). Self presentation. In M.R. Leary \& J.P. Tangey (Eds.) Handbook of Self and Identity. (pp. 542-570)). New York: Guilford.

Segal, S. P., Baumohl, J., \& Moyles, E. W. (1980). Neighborhood types and community reaction to the mentally ill: A paradox of intensity. Journal of Health and Social Behavior, 21, 345-359.

The Cabinet Office 2010, "Building the Big Society" available at https://www.gov.uk/government/publications/building-the-big-society, (access January 7 , Formatted: Font: Times New Roman, $12 \mathrm{pt}$ Formatted: Indent: Left: 0 ", Hanging: $0.5 "$, Space After: $10 \mathrm{pt}$ 2014). Formatted: Font: Calibri, $11 \mathrm{pt}$

Townley, G., Kloos, B., \& Wright, P. (2009). Understanding the experience of place: Expanding methods to conceptualize and measure community participation of persons with severe mental illness. Health Place, 15, 520-531.

Walker, P. (1999). From community presence to sense of place: Community experience of adults with developmental disabilities. The Journal of the Association for Severe Handicaps, 24, $23-33$ 
Warner, R. (2005). Recovery from Schizophrenia: Psychiatry and Political Economy. New York: Routledge.

World Health Organization. (2013). Comprehensive mental health action plan 2013-2020. Helsinki: World Health Organization.

Yanos, P. T., Barrow, S. M., \& Tsemberis, S. (2004). Community integration in the early phase of housing among homeless persons diagnosed with severe mental illness: Successes and challenges. Community Mental Health Journal, 40(2), 133-150.

Yanos, P., Felton, B., Tsemberis, S., \& Frye, V. (2007). Exploring the role of housing type, neighbourhood characteristics, and lifestyle factors in the community integration of formerly homeless persons diagnosed with mental illness. Journal of Mental Health, 16, 703-71 
Table 1: Demographic Summary

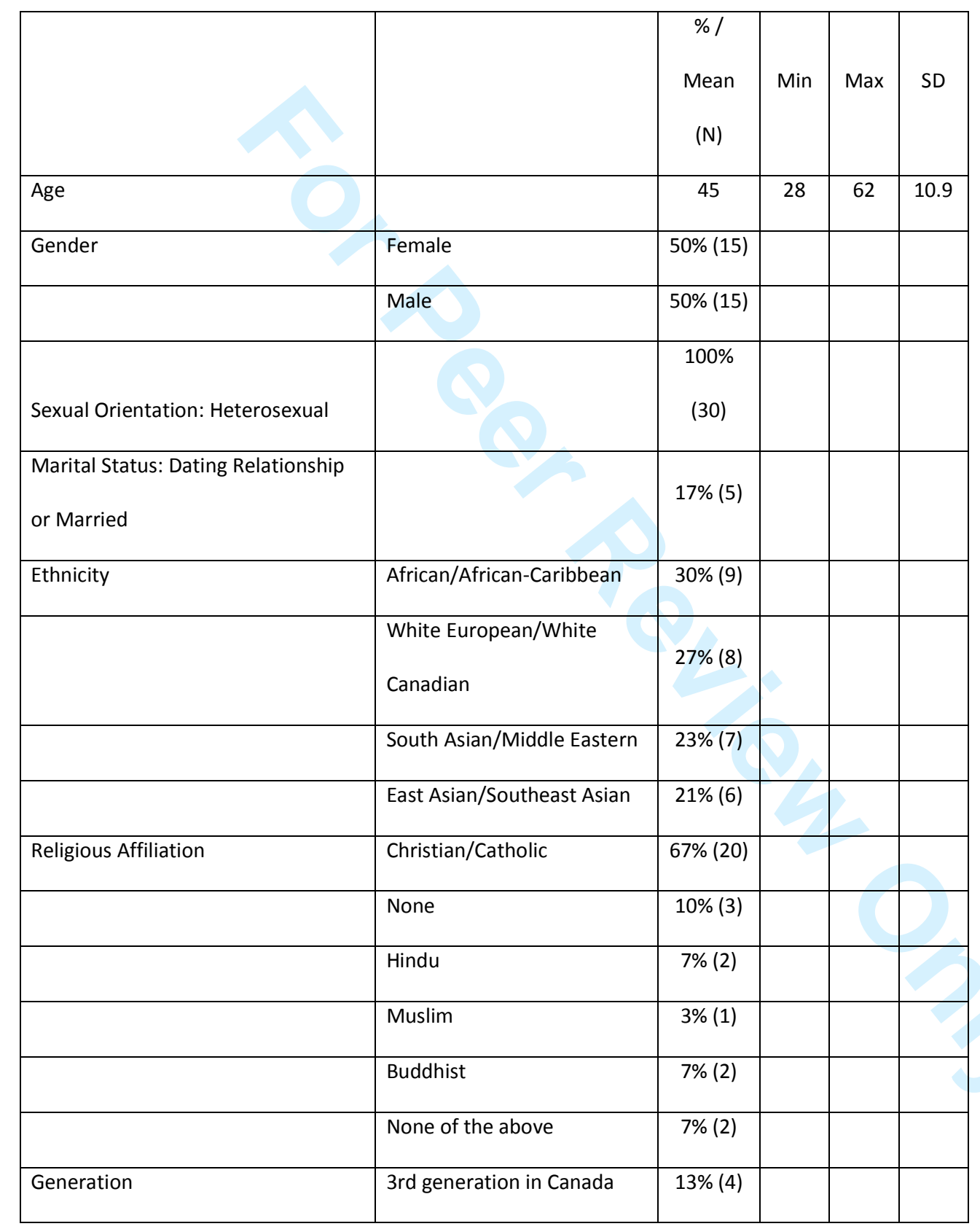

URL: http://mc.manuscriptcentral.com/ajpr Email: ksokol@iit.edu 


\begin{tabular}{|c|c|c|c|c|c|}
\hline & 2nd generation in Canada & $13 \%(4)$ & & & \\
\hline & 1st generation in Canada & $60 \%(18)$ & & & \\
\hline $\begin{array}{l}\text { Years in Canada (for 1st genera } \\
\text { participants) } N=18\end{array}$ & & 24 & 8 & 48 & 10 \\
\hline \multirow[t]{2}{*}{ Citizenship } & Canadian Citizens & $80 \%(24)$ & & & \\
\hline & Permanent Resident & $20 \%(6)$ & & & \\
\hline \multicolumn{6}{|l|}{$\begin{array}{l}\text { Immigration Path (for 1st and 2nd } \\
\text { generation) } \mathrm{N}=18\end{array}$} \\
\hline & Family Sponsorship & $64 \%(14)$ & & & \\
\hline & Refugee & $23 \%(5)$ & & & \\
\hline & Other & $5 \%(1)$ & & & \\
\hline \multirow[t]{5}{*}{ Employment Status } & $\begin{array}{l}\text { Not in the labour force (not } \\
\text { working, not looking) }\end{array}$ & $53 \%$ (16) & & & \\
\hline & $\begin{array}{l}\text { Unemployed (not working } \\
\text { and looking) }\end{array}$ & $3 \%(1)$ & 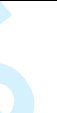 & & \\
\hline & Student & $13 \%(4)$ & & & \\
\hline & Volunteer & $23 \%(7)$ & 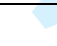 & & \\
\hline & $\begin{array}{l}\text { Occasional } \\
\text { Employment/Work Program }\end{array}$ & $7 \%(2)$ & & & \\
\hline Age first diagnosed & & 28 & 7 & 55 & 9.8 \\
\hline Years since last hospitalization & & 7 & 1.5 & 29 & 9 \\
\hline Number of hospitalizations & & 4 & 0 & 27 & 6.3 \\
\hline Housing & Family & $3 \%(1)$ & & & \\
\hline
\end{tabular}


